\title{
Relation of the infrasound characteristics and the continuous steel bridge vibration modes generated by the vibration of moving heavy trucks
}

\author{
Saiji FUKADA ${ }^{1^{*}}$, Hirokazu HAMA ${ }^{2}$, Kimihisa USUI ${ }^{2}$ \\ 1. School of Environmental Design, Kanazawa University, Kakuma-Machi, Kanazawa City, Ishikawa Pref., 920-1192, Japan \\ 2. Fuji Engineering Co., Ltd., 5-5-28 Higashimikuni, Yodogawa-Ku, Osaka City, Osaka Pref., 532-0002, Japan
}

\begin{abstract}
As heavy trucks pass over highway bridges, bridge vibration occurs and generates infrasound. General trucks in Japan with rear leaf suspension have whole body vibration (suspension spring vibration) frequencies of about $3 \mathrm{~Hz}$. Also, the frequencies of the wheel vibration (tire spring vibration) are about $10-20 \mathrm{~Hz}$. The continuous steel highway bridges with middle span length have vibration modes with the same phase in each span at the frequencies of about $3 \mathrm{~Hz}$ and also have those with the secondary mode shape at the frequencies of about $10-20 \mathrm{~Hz}$. Truck vibrations and bridge vibrations are closely related. In this work, vibration tests are conducted using a heavy test truck for two cases of infrasound complaints in order to investigate the relation between the continuous steel bridge vibration modes generated by the vibration of moving heavy trucks and its infrasound characteristics. As a result of the examination, two types of bridge vibration modes are caused by the vibrations of a moving heavy truck. Moreover, the bending vibration modes with the same phase in each span have the most powerful infrasound pressure, since each span vibrates with the same phase. Two countermeasures, including viscoelastic damper at the end of the girders and extended deck method, are proposed to reduce the amplitude of bridge vibration and its infrasound.
\end{abstract}

Key words: infrasound; bridge vibration; truck vibration; viscoelastic damper; extended deck

C) 2012 JMT. All rights reserved.

\section{Introduction}

I nfrasound is one of structural noises in the frequency range from 0 to $20 \mathrm{~Hz}$. It is usually produced from the bridge vibration generated by the vibration due to moving heavy trucks, and houses near the bridge. As a result, the people living near the bridge can perceive the infrasound $(0-20 \mathrm{~Hz})$, and complain about a rattling sound and/or mental and physical discomfort, when the trucks are resonated with the bridge due to their close frequencies.

In Japan, the infrasound problems due to the vibration of the highway bridges in expressways were first reported in 1975 [1]. Theoretical analysis of the infrasound radiation from the highway bridge was conducted [2]. The ex-

This paper was presented at the 5th International Symposium on Environmental Vibration in Chengdu, China, October 2022,2011 , and recommended by the scientific committee of the symposium to JMT

Received Dec. 12, 2011; revision accepted Apr. 27, 2012

*Corresponding author. Tel.: +81-76-234-4605, Fax: +81-76-

234-4605, E-mail: saiji@t.kanazawa-u.ac.jp

(C) 2012 JMT. All rights reserved

doi: 10.3969/j.issn.2095-087X.2012.03.009 perimental study about human perception for the infrasound was also carried out to discover the perception threshold of the infrasound [3]. Recently, the predictions of the infrasound or the sound near the bridge were investigated using the finite element method and the boundary element method [4-6]. The active control method for the infrasound radiation was considered as well [7].

However, it is not enough to investigate the relation of the human perception for the infrasound and the bridge vibration modes caused by moving heavy trucks. In order to reduce the amplitude of the vibration mode that causes the infrasound problem, it is necessary to investigate this relation and the countermeasures.

In our past studies, experiments were conducted for the concrete bridge with short spans, aiming to clarify the relation between the infrasound and the bridge vibration modes [8-9]. According to the experimental results, it was clear that the concrete bridge with short spans had the frequencies close to the frequency of the tire spring vibration $(10-20 \mathrm{~Hz})$. It was also observed that the infrasound problem probably occurred due to the resonance between the concrete bridge vibration and the tire spring vibration $(10-20 \mathrm{~Hz})$. The occurrence of the infrasound radiation from the concrete bridge with short 
spans was related to the tire spring vibration and the bridge vibration.

On the other hand, the continuous steel bridge with medium-length spans has the frequencies close to the frequencies of the trucks' leaf suspension spring vibration $(3 \mathrm{~Hz})$ and the tire spring vibration $(10-20 \mathrm{~Hz})$. Experiments on continuous steel bridge with mediumlength spans were conducted to address the relationship between the infrasound and bridge vibration modes due to the vibration of the moving heavy trucks.

\section{Characteristics of infrasound, bridge vi- bration, and truck vibration}

\subsection{Truck vibration}

Fig. 1(a) shows the spectrum of acceleration in each measured point ( $A_{\mathrm{s}}$ and $A_{\mathrm{t}}$; see Fig. 1(b)), when an ordinary truck with rear leaf suspension [10] runs on the pavement. According to Fig. 1(a), frequency of the whole body vibrations [11] in Japanese trucks with rear leaf suspension appears at about $3.0 \mathrm{~Hz}$ [12]. In other countries, this value is at $1.5-4.5 \mathrm{~Hz}$ [13]. Also frequencies of wheel vibrations [13], such as wheelhop mode, appear at about $10-20 \mathrm{~Hz}$. In this study, whole body vibration and wheel vibration are defined as leaf suspension spring vibration and tire spring vibration, respectively.

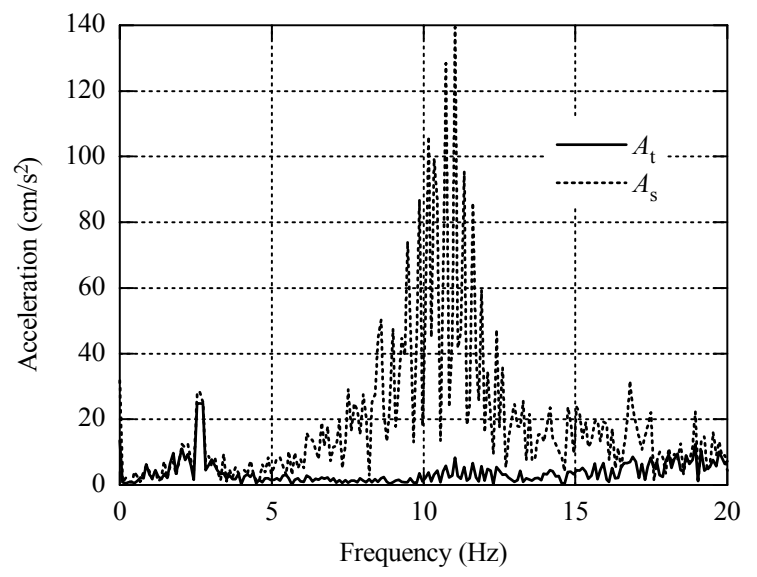

(a) Spectrum

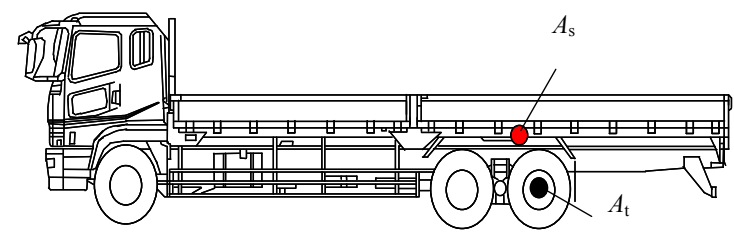

(b) Measured points

Fig. 1 Frequency characteristics of truck vibration

\subsection{Bridge vibration modes}

The continuous steel bridges with medium span length $(20-40 \mathrm{~m})$ have the vibration modes with the same phase in each span at the frequencies of the truck's suspension spring vibration (about $3 \mathrm{~Hz}$ ), as shown in Fig. 2(a). They also have the secondary mode shape at the frequencies of the truck's tire spring vibration (about 10-20 Hz), as shown in Fig. 2(b).

When the frequencies of each truck's vibration (the truck's suspension spring vibration and/or the tire spring vibration) and the bridge vibration are close, the bridge vibrates greatly because of the resonance.

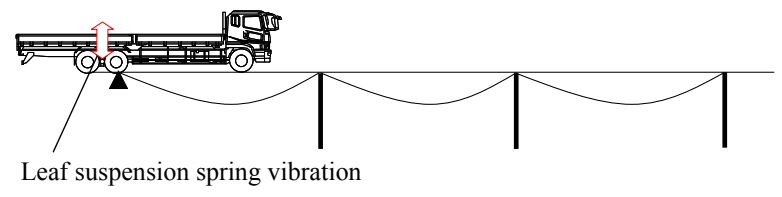

(a) Vibration modes (about $3 \mathrm{~Hz}$ ) with the same phase

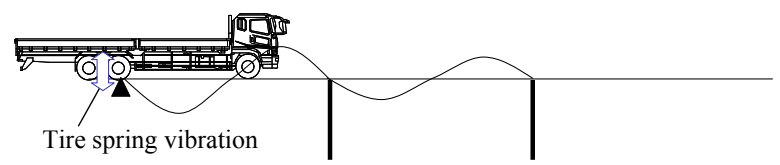

(b) Vibration modes (about 10-20 Hz) with secondary mode shape

Fig. 2 Bridge vibration modes

\subsection{Reference values for the infrasound}

In Japan, the infrasound is estimated using the two curves as shown in Fig. 3, which are reference values of the one-third octave band frequency for the complaints about the rattling sound and mental and physical discomfort, proposed by the Ministry of Environment (Japan) [14]. The red line is the threshold level that the windows begin to rattle and the human perceives the rattling sound. The blue line is the threshold level that the human perceives the mental and physical discomfort.

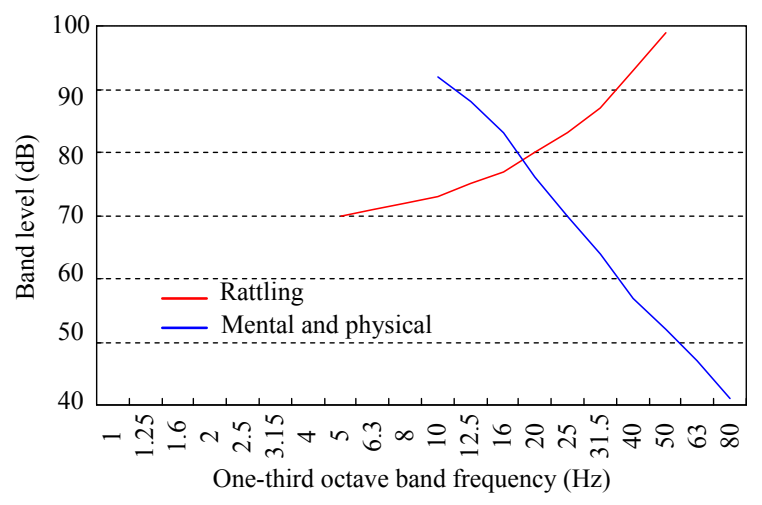

Fig. 3 Reference values of the infrasound 
When the frequencies of the truck's suspension spring vibration (about $3 \mathrm{~Hz}$ ) and/or the tire spring vibration (about $10-20 \mathrm{~Hz}$ ) and the bridge vibration modes are close, complaints about a rattling sound and/or complaints about mental and physical discomfort occur.

\section{Experimental results of case 1}

\subsection{Outline of the object bridge}

The object bridge of case 1 [15] is a three-span continuous steel girder bridge located over a small ravine, as shown in Fig. 4(a). The span arrangement is $26.0 \mathrm{~m}+33.0 \mathrm{~m}+26.0 \mathrm{~m}$. All of the substructures are spread foundations on the firm stratum. The measured points are shown in Fig. 4(b). The measured items are the acceleration and infrasound pressure at the bridge and at the houses.

\subsection{Vibration characteristics}

The residents who live near the highway bridge perceived the infrasound (rattling sound) transmitted from the $A 2$ expansion joint of the bridge. We investigated the characteristics of acceleration at the bridge deck and the resulting infrasound on the houses, when a test truck or an ordinary truck passes over the bridge.

When a test truck passes over the bridge, the acceleration of the deck at the bridge ( $A 2$ side) and the infrasound pressure at the 2 nd floor of a given residence (house $A$ ) are shown in Fig. 5(a) and Fig. 5(b), respectively, where $L$ is the length of side span from $P 2$ to $A 2$. The peak frequencies $3.2 \mathrm{~Hz}, 4.7 \mathrm{~Hz}$ and $5.5 \mathrm{~Hz}$ are observed in the spectrum of acceleration at the deck (Fig. 5(a)). The same frequencies were observed in the spectrum of infrasound at the 2 nd floor of house $A$ (Fig. 5(b)).

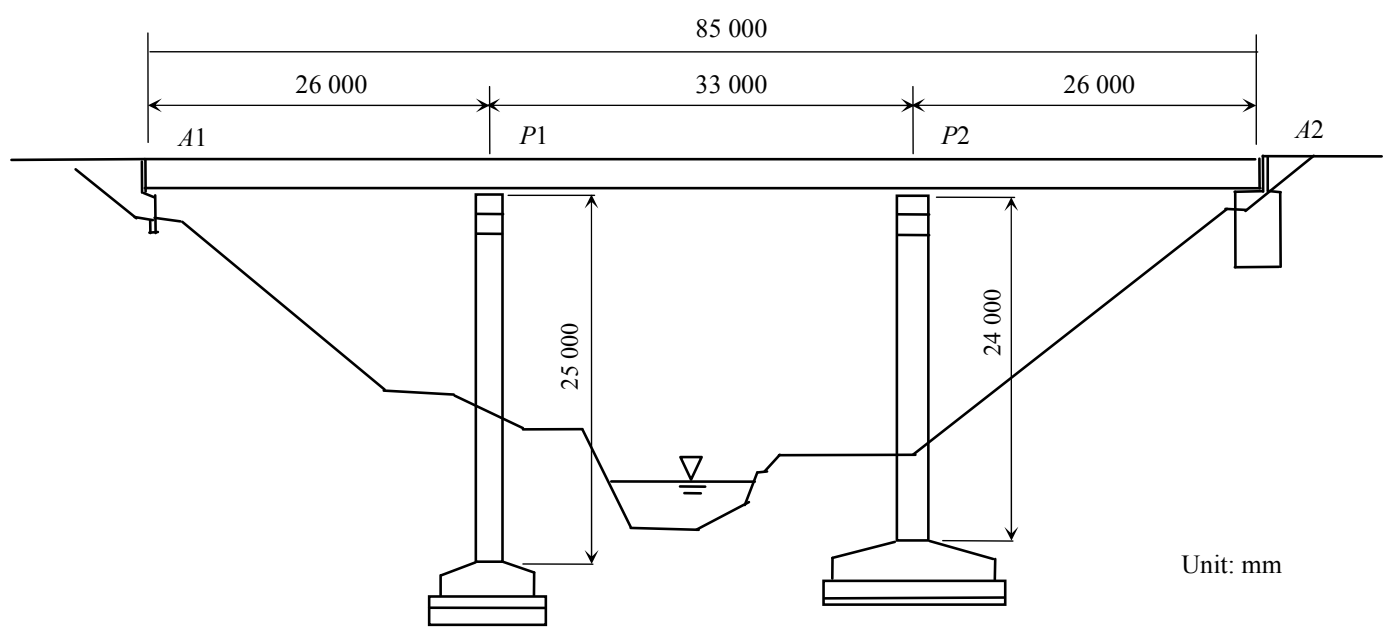

(a) Side view
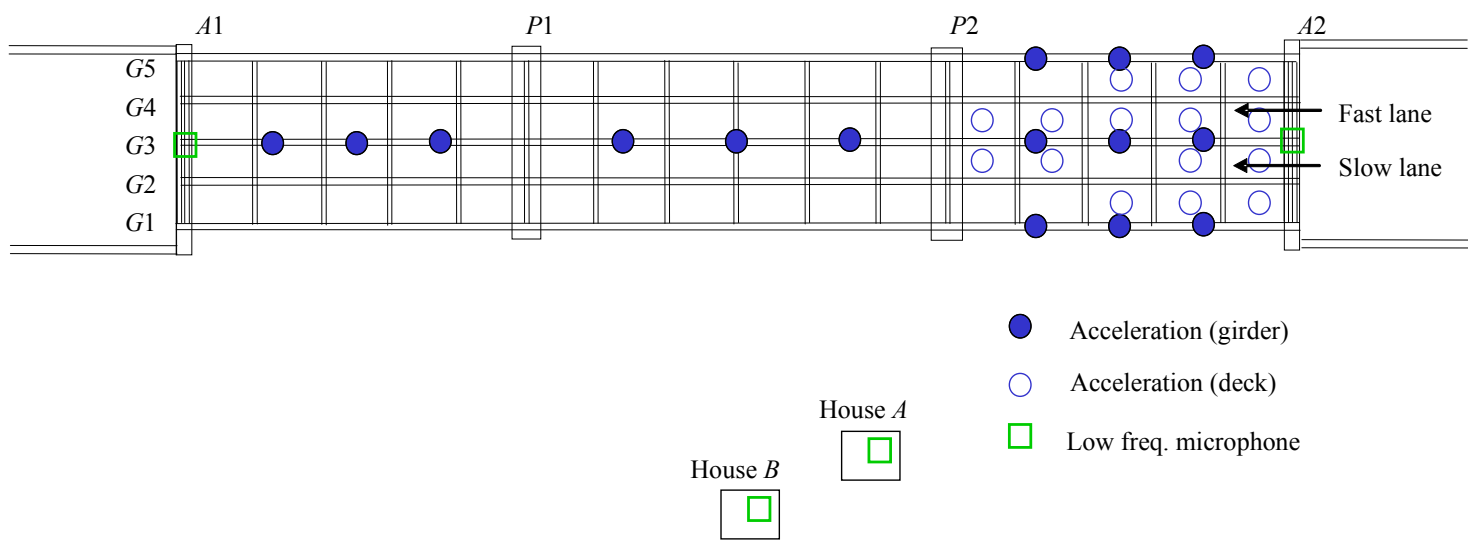

(b) Plan view and measured points

Fig. 4 Object highway bridge of case 1 

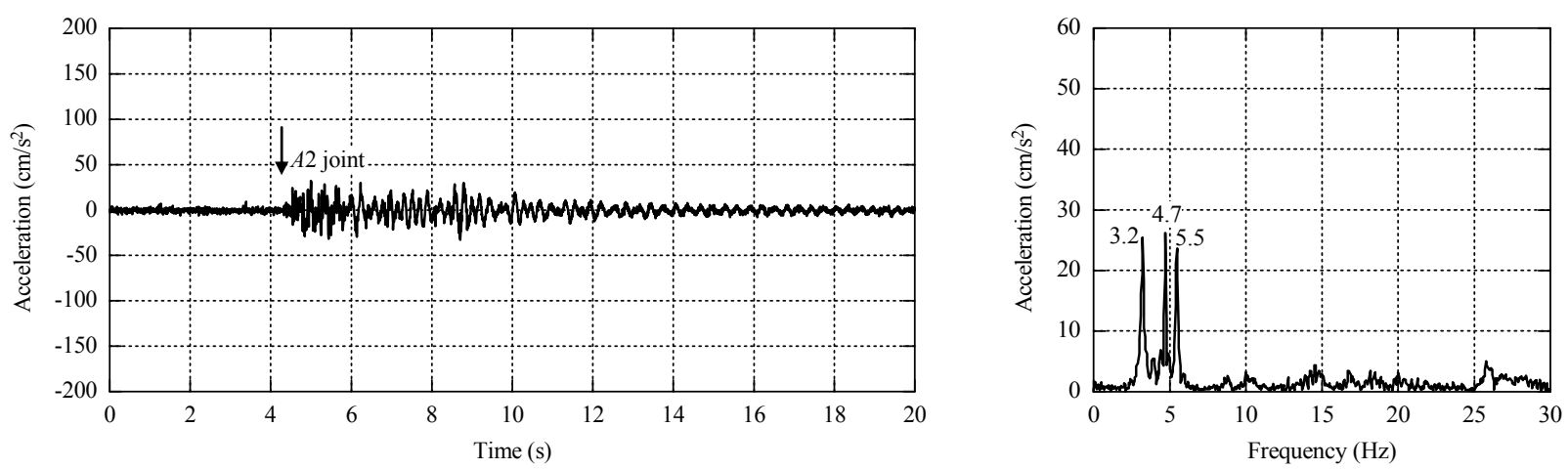

(a) Acceleration spectra of the deck $(A 2$ side, $L / 4)$
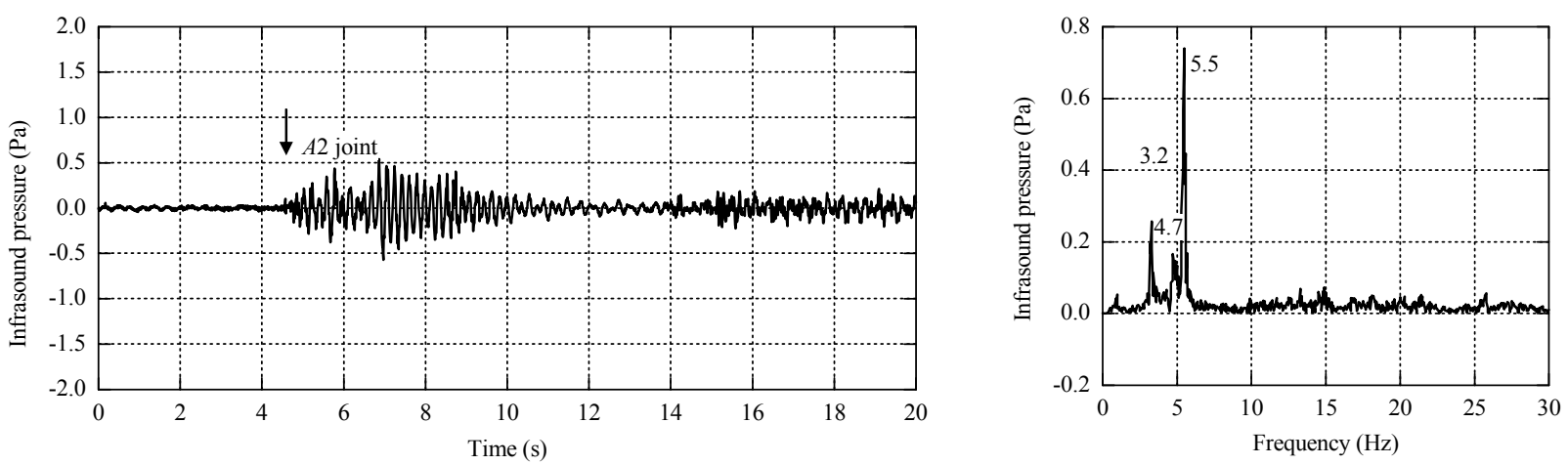

(b) Infrasound pressure spectra of the 2nd floor (house $A$ )

Fig. 5 Case of a test truck
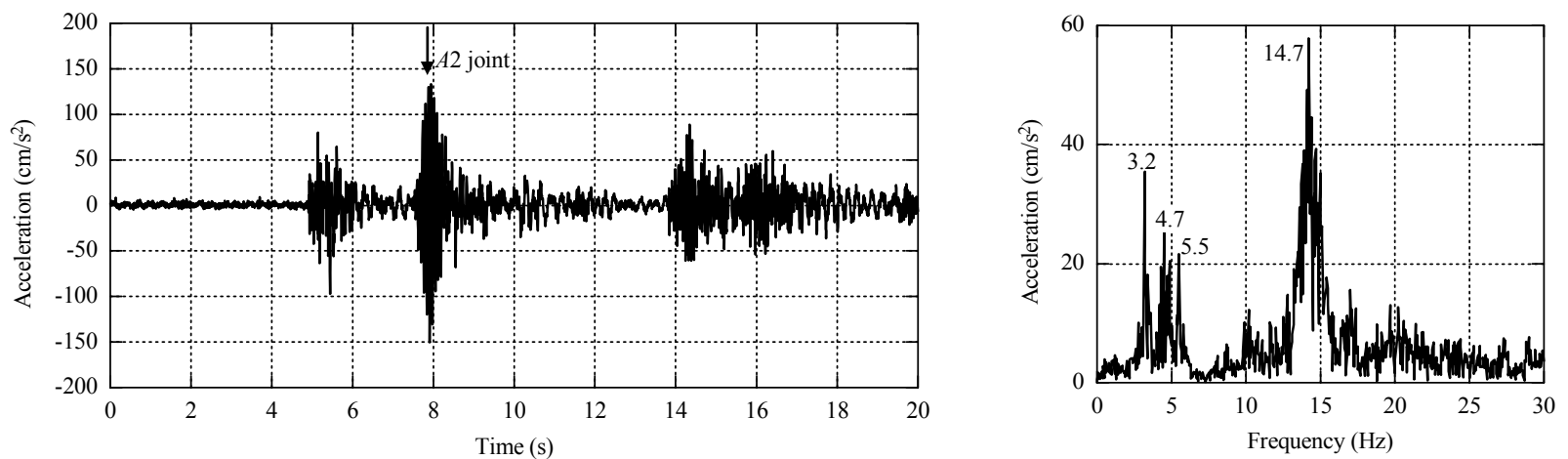

(a) Acceleration spectra of the deck $(A 2$ side, $L / 4)$
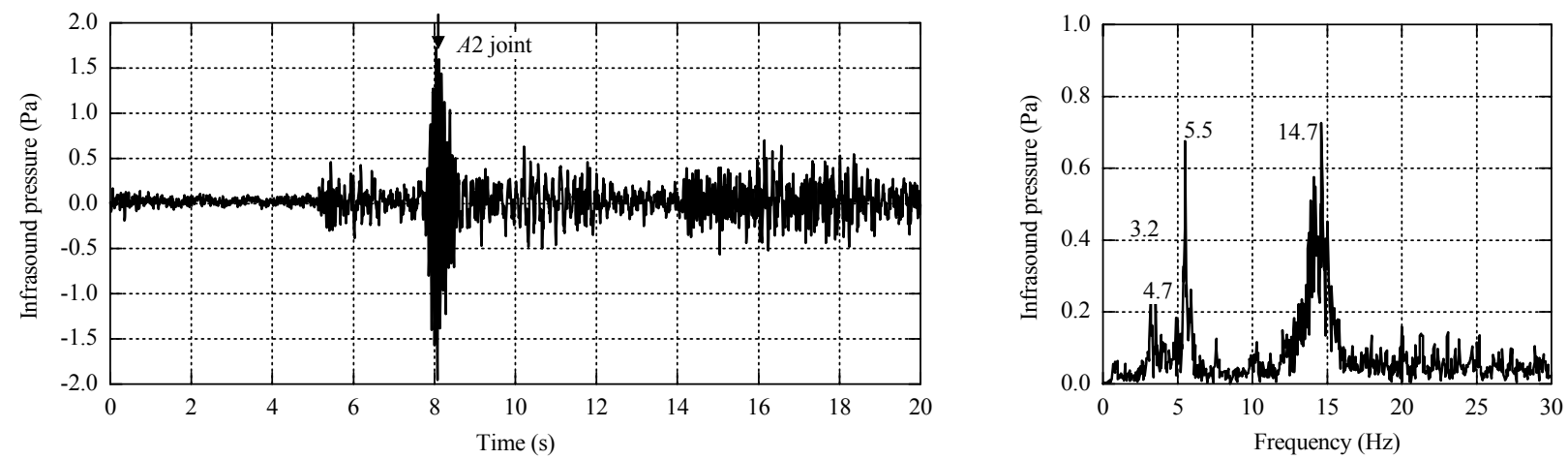

(b) Infrasound pressure spectra of the 2nd floor (house $A$ )

Fig. 6 Case of an ordinary truck 
In the same way, the acceleration and the infrasound pressure when an ordinary truck runs over the bridge are shown in Fig. 6(a) and Fig. 6(b), respectively. The impact vibrations (about $8 \mathrm{~s}$ ) coincide with the time of the truck passing over the $A 2$ expansion joint. The peak frequencies $3.2 \mathrm{~Hz}, 4.7 \mathrm{~Hz}$ and $5.5 \mathrm{~Hz}$ were observed in the spectrum of the acceleration (Fig. 6(a)) and the infrasound (Fig. 6(b)). And a frequency of $14.7 \mathrm{~Hz}$ was seen when an ordinary truck, as opposed to the test truck, passed over the bridge.

The frequency of the tire spring vibration in the test truck was $10.4 \mathrm{~Hz}$. Since the bridge vibration at the frequency of $14.7 \mathrm{~Hz}$ was not generated by the tire spring vibration of the test truck, we can conclude that infrasound does not radiate to nearby houses when the testtruck passes over the $A 2$ expansion joint. However, according to the results of other examinations when an ordinary truck passes, it is clear that bridge vibration is transmitted to houses as infrasound, and that the bridge vibration $(14.7 \mathrm{~Hz})$ greatly affects residents.

\subsection{One-third octave band frequency}

Fig. 7 shows the average 1/3 octave band frequency of the infrasound measured in two days on the 2 nd floor of both houses $A$ and $B$. The frequencies $3.15-5.0 \mathrm{~Hz}$ and $12.5-16.0 \mathrm{~Hz}$ appeared at the 2nd floor of the house $A$ and house $B$. Therefore, it turned out that the two houses were influenced by the object bridge vibration modes at $3.15-5.0 \mathrm{~Hz}$ and $12.5-16.0 \mathrm{~Hz}$. Also, compared to the one-third octave band frequencies with the reference values for the complaints about the rattling sound and for the complaints about mental and physical discomfort by the Ministry of Environment (Japan), it is clear that these levels of the house $A$ and house $B$ are larger than the rattling sound curve at $3.15-5.0 \mathrm{~Hz}$ and that the house $A$ is almost the same as that at 12.5$16.0 \mathrm{~Hz}$.

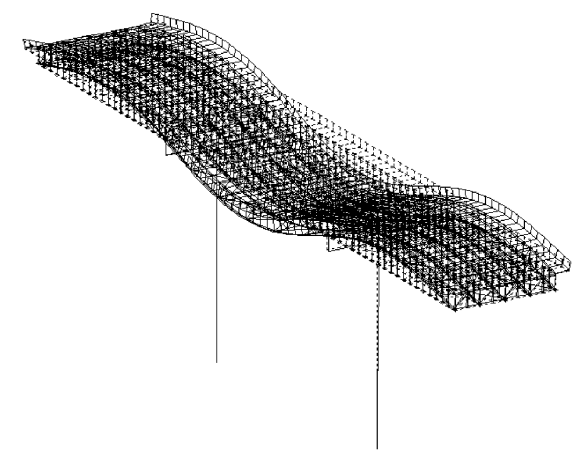

(a) Bending symmetry 1st (exp.: $3.2 \mathrm{~Hz}$, anal.: $3.0 \mathrm{~Hz}$ )

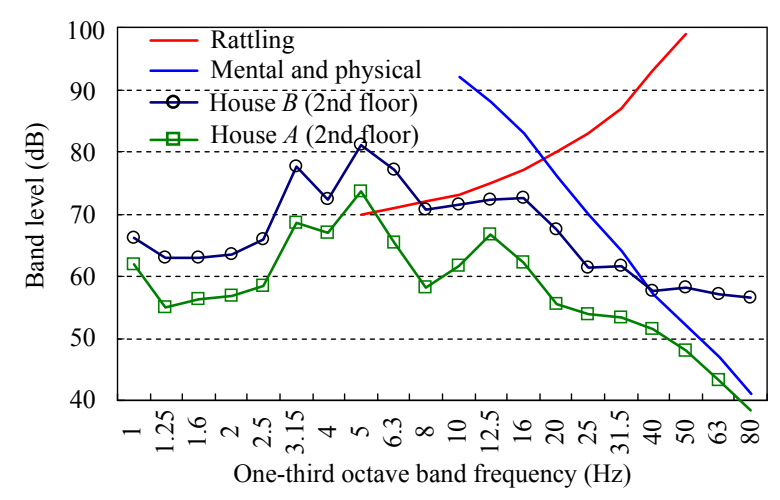

Fig. 7 One-third octave band frequency of the infrasound at the house $A$ and house $B$

\subsection{Bridge vibration modes of case 1}

Fig. 8 shows the vibration characteristics of case 1 at the frequencies of $0-15 \mathrm{~Hz}$. The frequencies identified by the experiment are indicated in the figure and compared with the frequencies of the analysis. According to the results of the analysis, the bridge vibration mode of $5.5 \mathrm{~Hz}$ was the 2 nd symmetric bending mode with the same phase in each span (Fig. 8(e)). Additionally, the vibration mode of $14.2-14.7 \mathrm{~Hz}$ was the bending vibration mode with the secondary mode shape at the side spans (Fig. 8(j)). It is clear that the 2nd symmetric bending mode $(5.5 \mathrm{~Hz})$ (Fig. $8(\mathrm{e})$ ) with the same phase in each span (Fig. 2(a)) affects the house $A$ and house $B$. Since each span vibrates with the same phase, it seems that the most powerful infrasound pressure is transmitted to the house $A$ and house $B$.

Moreover, the bending vibration mode $(14.2-14.7 \mathrm{~Hz})$ (Fig. 8(j)) with the secondary mode shape at the side spans (Fig. 2(b)) also affects the house $A$. It seems that this vibration mode was generated by the trucks' tire spring vibration passing over the roughness (faulting) at the $A 2$ expansion joint.

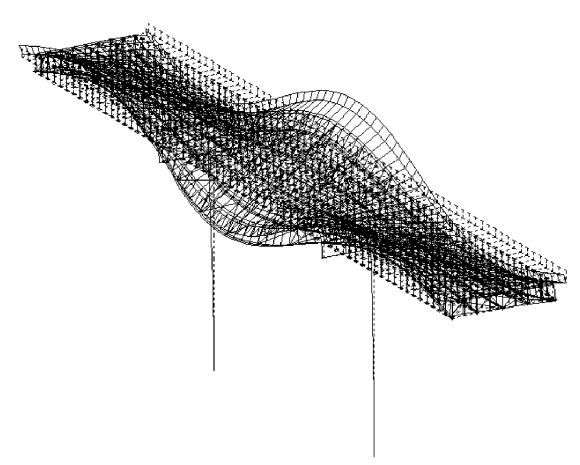

(b) Torsion 1st (anal.: $3.9 \mathrm{~Hz}$ )

Fig. 8 Vibration characteristics (case 1) 


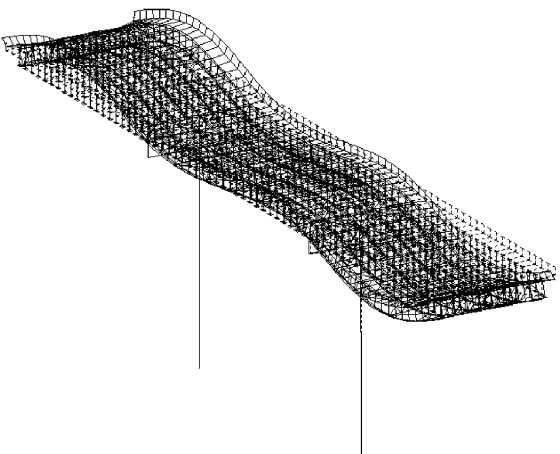

(c) Bending asymmetry 1st (exp.: $4.7 \mathrm{~Hz}$, anal.: $4.4 \mathrm{~Hz})$

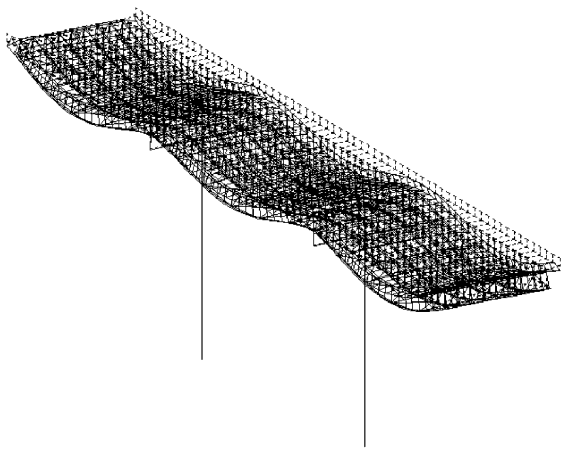

(e) Bending symmetry 2nd (exp.: $5.5 \mathrm{~Hz}$, anal.: $5.3 \mathrm{~Hz}$ )

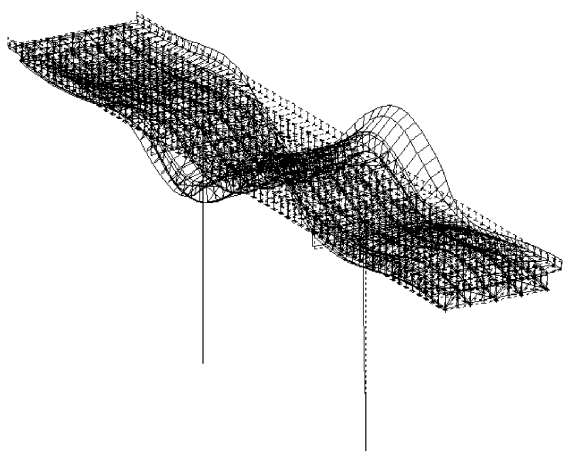

(g) Bending asymmetry (anal.: $9.8 \mathrm{~Hz})$

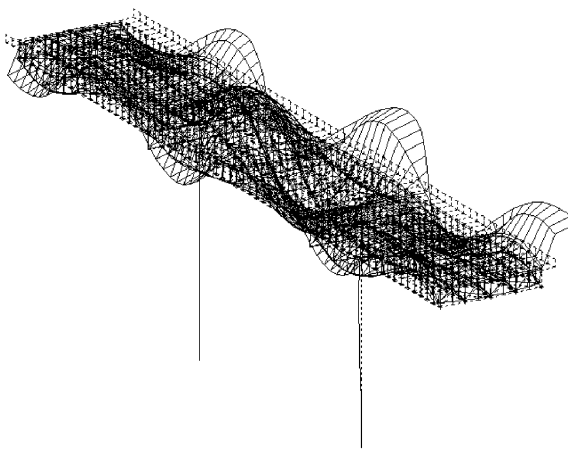

(i) Bending (anal.: $12.9 \mathrm{~Hz}$ )

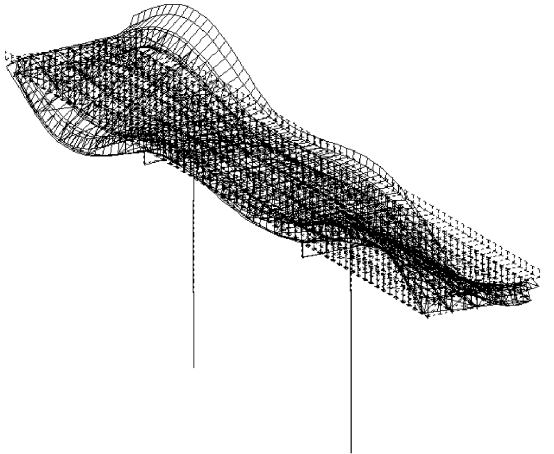

(d) Torsion 2nd (anal.: $5.1 \mathrm{~Hz})$

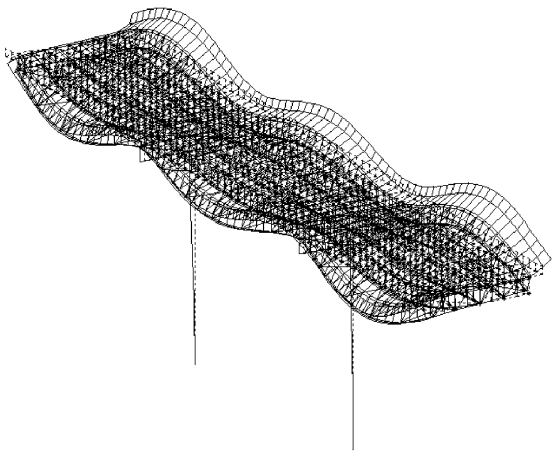

(f) Torsion 3rd (anal.: $5.7 \mathrm{~Hz})$

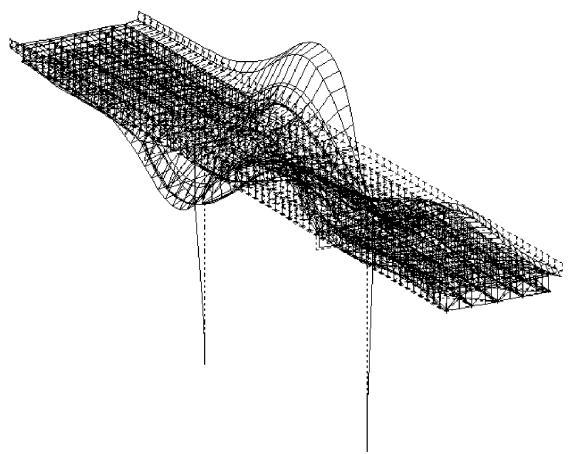

(h) Torsion (anal.: 10.0 Hz)

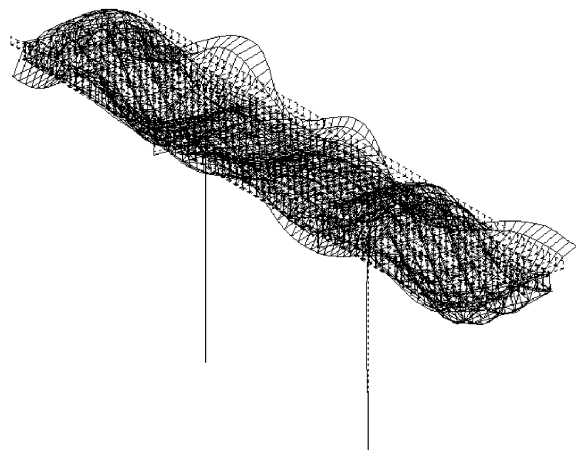

(j) Bending at side spans (exp.: 14.2-14.7 Hz, anal.: $15.0 \mathrm{~Hz}$ )

Fig. 8 (Continued) 


\section{Experimental results of case 2}

\subsection{Outline of the object bridge}

The object bridges of case 2 [16] are comprised of two lanes: one bridge with two eastbound lanes parallel to the other bridge with two westbound lanes, as shown in Fig. 9(c).

The eastbound bridge comprises a simple steel composite girder bridge with a $25.2 \mathrm{~m}$ span and a continuous steel composite girder bridge with three $49.0 \mathrm{~m}$ spans constructed in 1967, as shown in Fig. 9(a) and Fig. 9(c).
On the other hand, the westbound bridge comprises a simple steel composite girder bridge with a $36.47 \mathrm{~m}$ span and a continuous steel composite girder bridges with three spans $(48.59 \mathrm{~m}, 49.09 \mathrm{~m}$ and $49.09 \mathrm{~m})$ constructed in 1972, as shown in Fig. 9(b) and Fig. 9(c). The simple composite girder bridges $(A 1-P 1)$ of the westbound and eastbound bridges are jointed with continuous bridges $(P 1-P 4)$.

The measured items were (a) the displacement of the superstructure; (b) the acceleration of the superstructure's vibration; and (c) the infrasound measured by low frequency microphones.

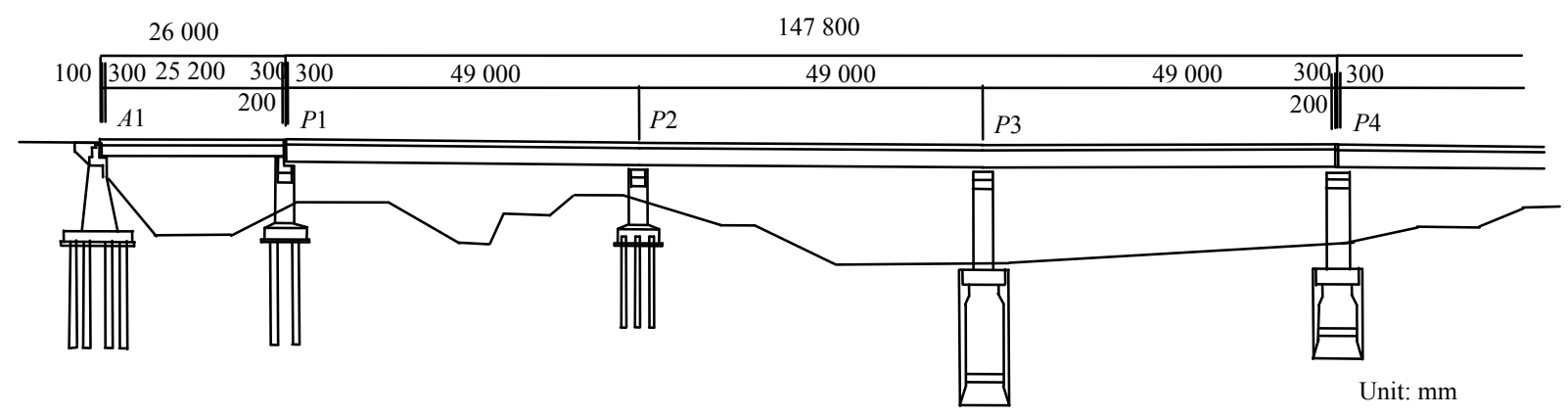

(a) Side view (eastbound bridge)

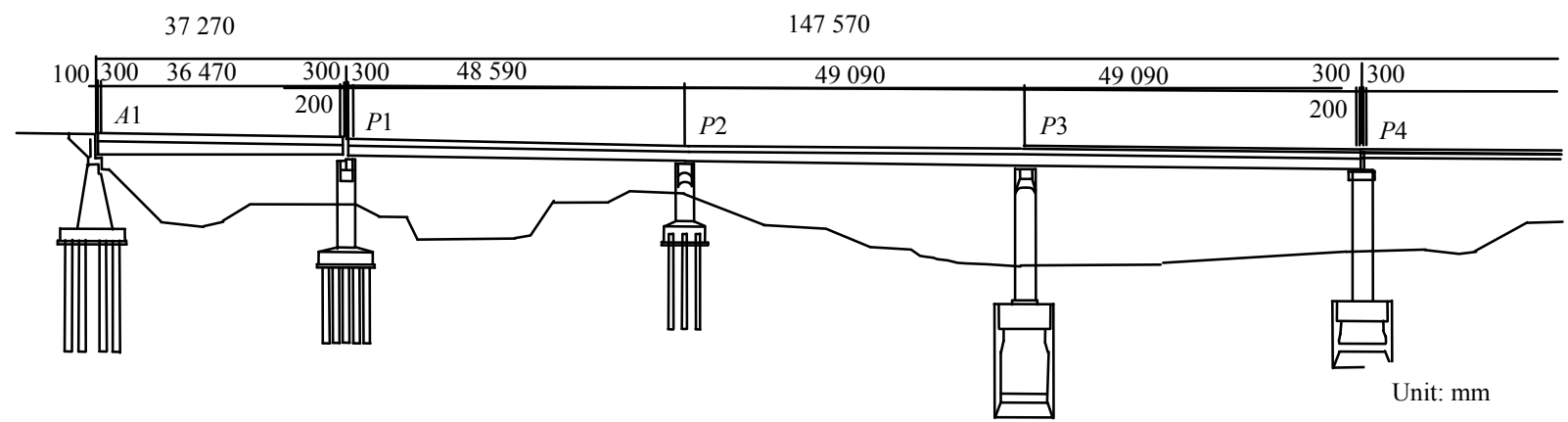

(b) Side view (westbound bridge)

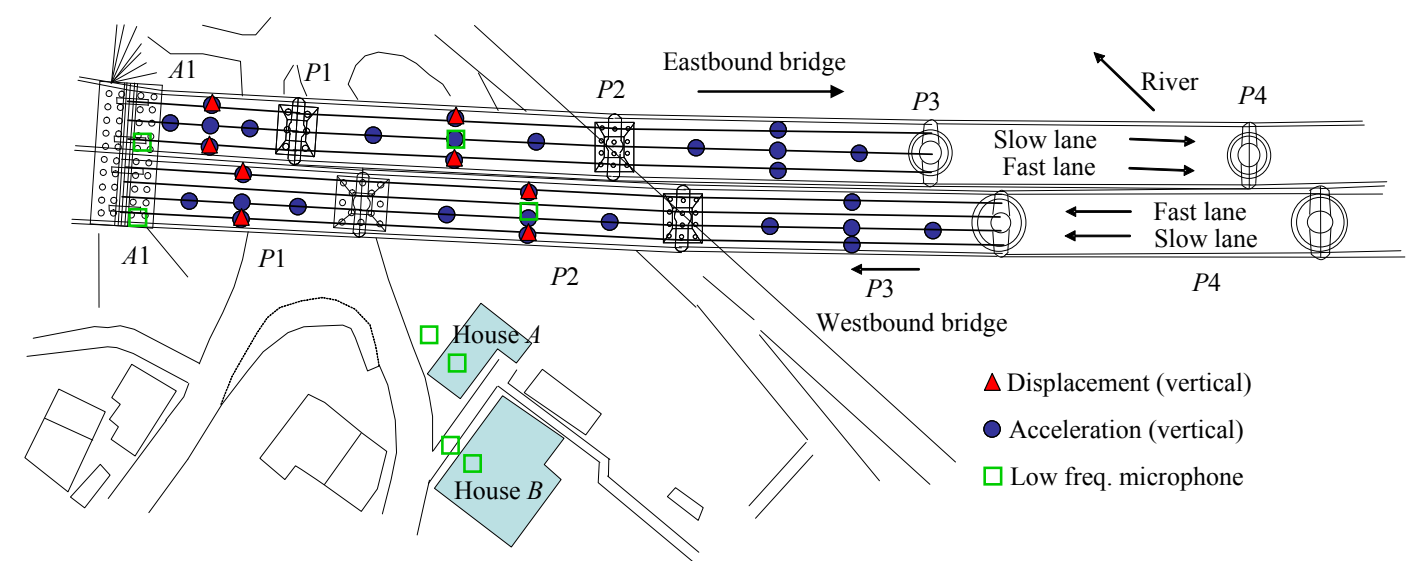

(c) Plane view and measured points

Fig. 9 Object highway bridge of case 2 (unit: $\mathrm{mm}$ ) 


\subsection{Vibration characteristics}

In order to compare the frequencies on the transfer paths of the infrasound, Fig. 10 shows the frequencies of infrasound pressure measured at (a) $A 1$ of eastbound bridge, (b) center of $P 1-P 2$ of westbound bridge and (c) outside of house $B$, when trucks pass on the eastbound and westbound bridges.

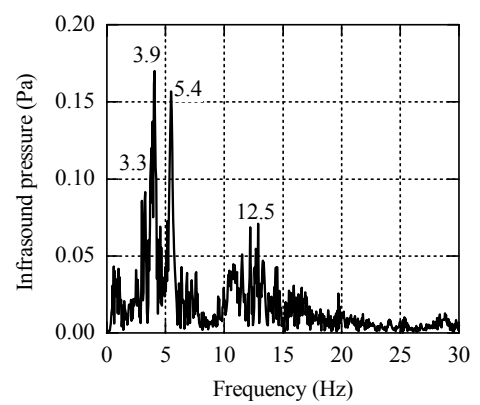

(a) $A 1$ (eastbound bridge)

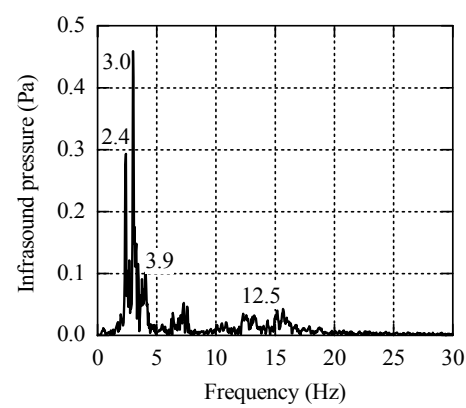

(b) $P 1-P 2$ (westbound bridge)

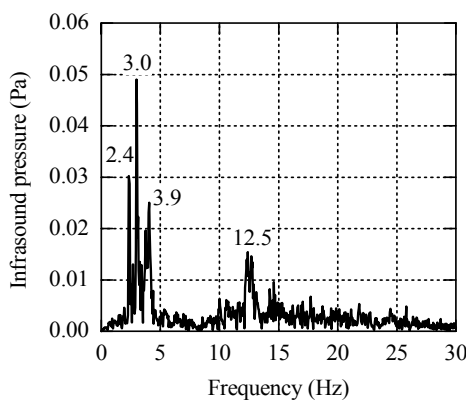

(c) House $B$ (outside)

Fig. 10 Frequencies of infrasound in each point

According to these spectrums, frequencies $0-5.5 \mathrm{~Hz}$ and $12.5 \mathrm{~Hz}$, corresponding to the vibration modes of the eastbound and westbound bridges, transmit to house $B$. In particular, the frequencies $(3.0 \mathrm{~Hz}$ and $12.5 \mathrm{~Hz})$ of the eastbound bridge and the frequencies $(2.4-2.5 \mathrm{~Hz}$ and $3.9 \mathrm{~Hz}$ ) of the westbound bridge affect house $B$.

\subsection{One-third octave band frequency}

In this case, the complaints about the rattling sound, which was produced by the infrasound radiated from the bridge, occurred in the house $A$ and house $B$ near the westbound bridge ( $P 1-P 2)$, as shown in Fig. 9(c). In order to investigate the causes of the complaints about the rattling sound, the infrasound caused by ordinary trucks was measured for 10 minutes per hour from 9:00 PM to 8:00 AM. Low frequency microphones were installed, as shown in Fig. 9(c). Fig. 11 shows the 1/3 octave band frequency of (a) the surrounding area of house $A$, (b) the 2nd floor of house $A$, (c) the surrounding area of e house $B$, and (d) the 1 st floor of house $B$.

The frequencies of $2.5-4.0 \mathrm{~Hz}$ and $12.5-16.0 \mathrm{~Hz}$ appear at house $A$ and house $B$ respectively. It turned out that the two houses were influenced by the vibration $(2.5-4.0 \mathrm{~Hz}$ and $12.5-16.0 \mathrm{~Hz})$ of westbound and eastbound bridges. Also, Fig. 11 shows the comparison of the $1 / 3$ octave band frequency with the reference values for the complaints about the rattling sound and for the complaints about mental and physical discomfort by Ministry of the Environment (Japan).

Though this rattling sound curve is only defined starting from $5 \mathrm{~Hz}$, it seems that these levels measured in the house $A$ and house $B$ are larger than the rattling sound curve of the reference values at the frequencies of 2.5-

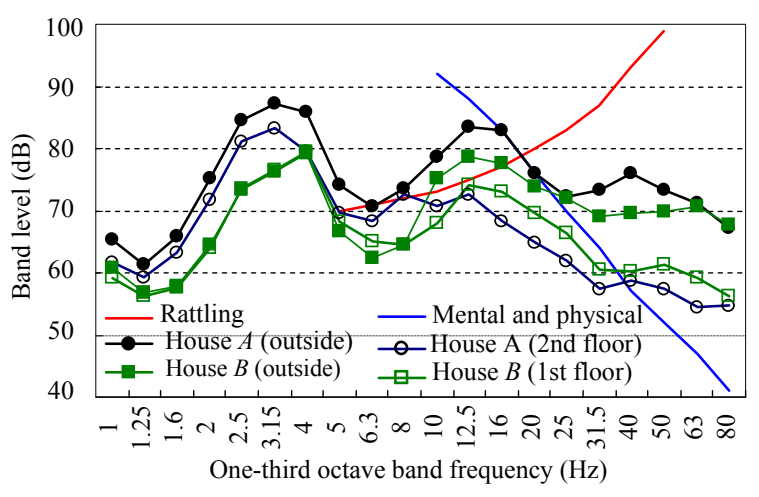

Fig. 11 One-third octave band frequency of the infrasound at the house $A$ and house $B$

4.0 Hz. Therefore, the house $A$ and house $B$ are more influenced by the infrasound at frequencies of $2.5-4.0 \mathrm{~Hz}$ radiated from the westbound and eastbound bridges.

\subsection{Bridge vibration modes of case 2}

Fig. 12 and Fig. 13 show the vibration characteristics of the westbound and eastbound bridges, respectively. The frequency identified by the experiment is indicated in the figure and compared with the frequencies of analysis. The two bridges have many similar vibration modes at frequencies of $0-4.0 \mathrm{~Hz}$. It is clear that the bending vibration modes of the two bridges with the same phase in each span (Fig. 2(a)), as shown in Fig. 12(b), (d), and (e) and Fig. 13(b) and (d), affect the house $A$ and house $B$ compared to the measured Onethird octave band frequency of the infrasound. Since each span vibrates with the same phase, the most powerful infrasound pressure is transmitted to the two houses, just like the object bridge of case 1 . 
Moreover, the bending vibration mode with the secondary mode shape at the side span (Fig. 2(b)), as shown in Fig. 13(f), also affects the two houses. It seems that this vibration was generated by the trucks' tire spring vibration passing over the roughness (faulting) at the $A 1$ expansion joint on the eastbound bridge.

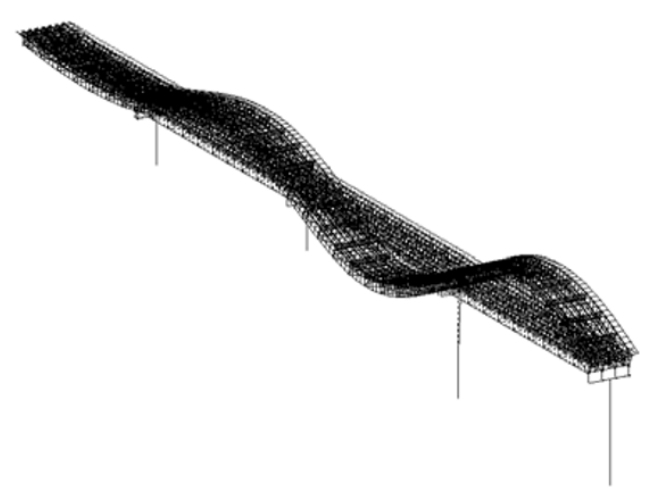

(a) Bending 1st (exp.: $1.9 \mathrm{~Hz}$, anal.: $1.8 \mathrm{~Hz})$

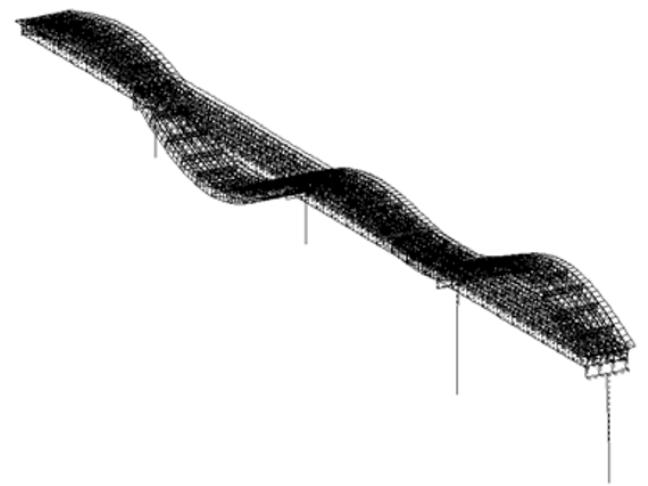

(b) Bending 2nd (exp.: 2.4-2.5 Hz, anal.: $2.4 \mathrm{~Hz}$ )

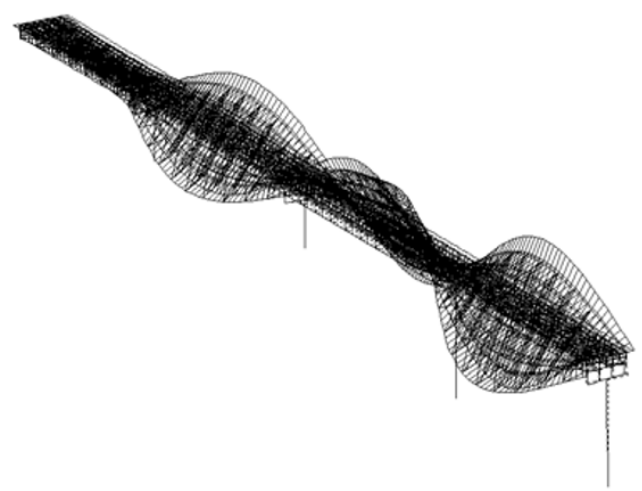

(c) Torsion (exp.: $2.7 \mathrm{~Hz}$, anal.: $3.1 \mathrm{~Hz})$

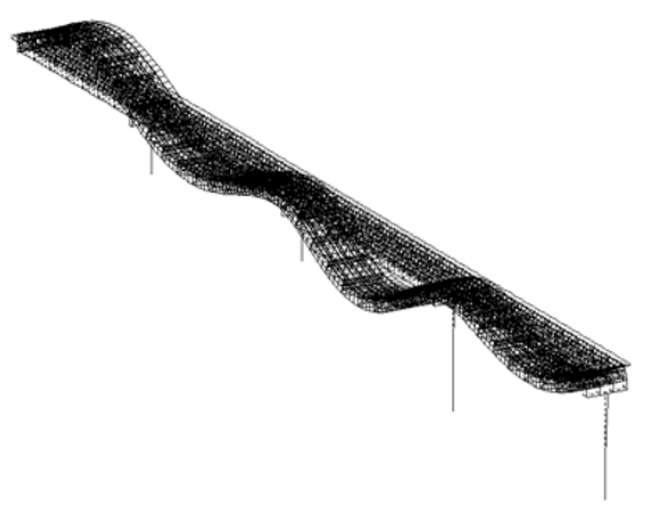

(d) Bending 3rd (exp.: $3.3 \mathrm{~Hz}$, anal.: $3.2 \mathrm{~Hz}$ )

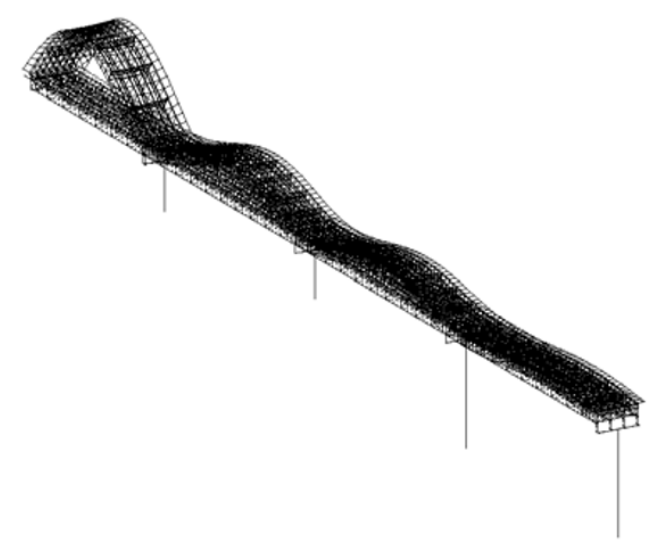

(e) Bending 4th (exp.: $3.9 \mathrm{~Hz}$, anal.: $3.9 \mathrm{~Hz})$

Fig. 12 Vibration characteristics of westbound bridge (case 2) 


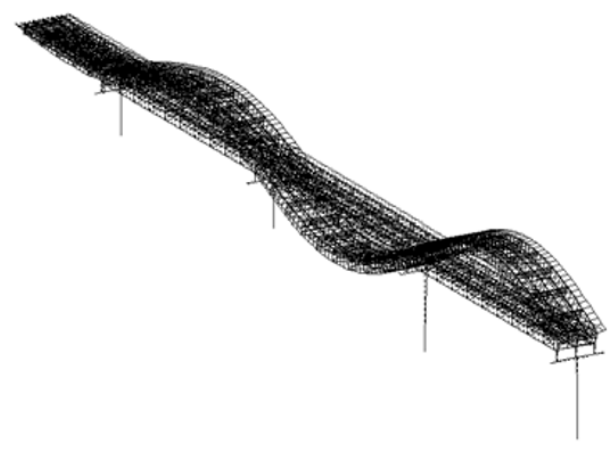

(a) Bending 1st (exp.: $1.9 \mathrm{~Hz}$, anal.: $1.9 \mathrm{~Hz})$

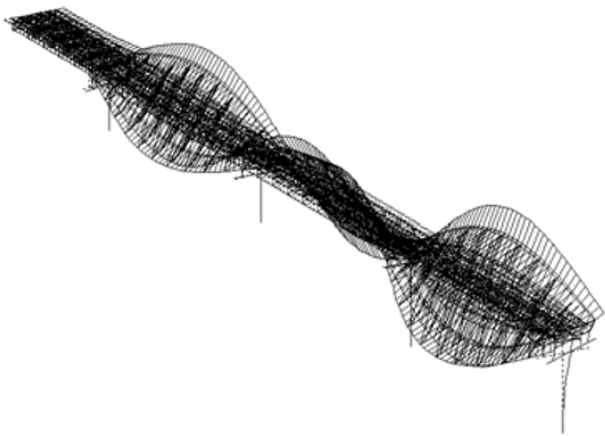

(c) Torsion (exp.: $3.4 \mathrm{~Hz}$, anal.: $3.1 \mathrm{~Hz})$

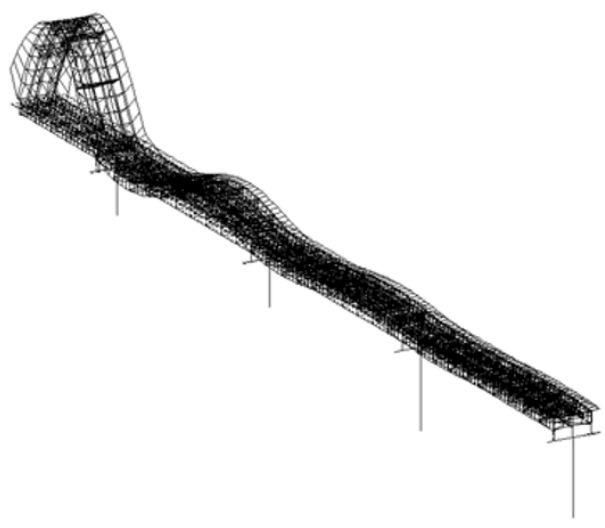

(e) Bending 4th (exp.: $5.4 \mathrm{~Hz}$, anal.: $5.5 \mathrm{~Hz})$

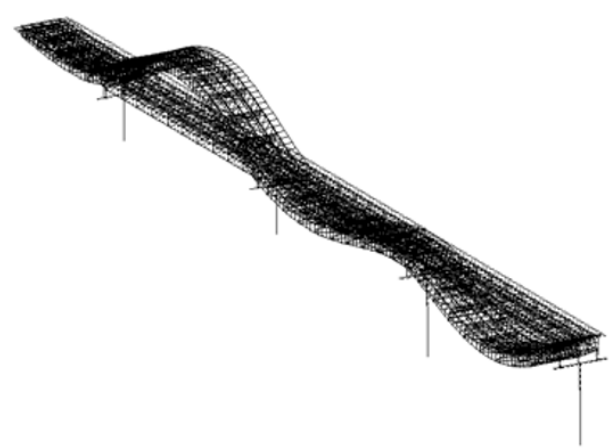

(b) Bending 2nd (exp.: $2.4 \mathrm{~Hz}$, anal.: $2.4 \mathrm{~Hz}$ )

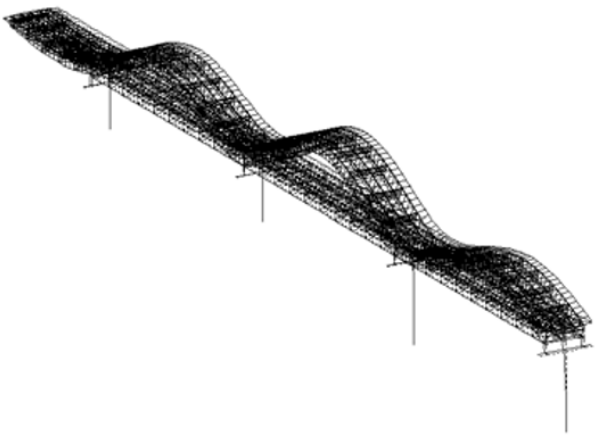

(d) Bending 3rd (exp.: $3.0 \mathrm{~Hz}$, anal.: $3.1 \mathrm{~Hz})$

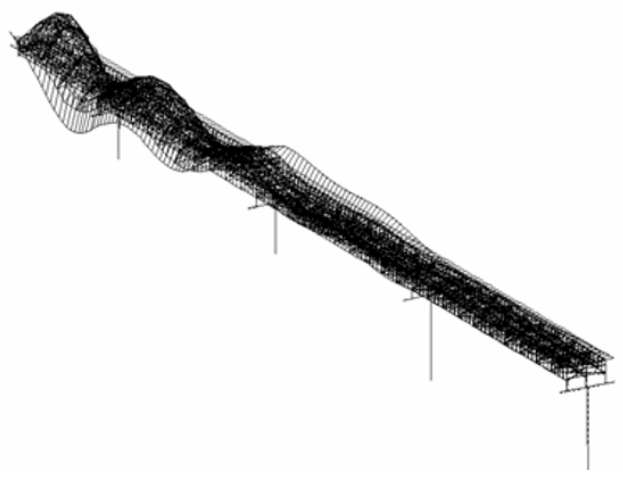

(f) Bending at side span (exp. and anal.: $12.5-16.0 \mathrm{~Hz}$ )

Fig. 13 Vibration characteristics of eastbound bridge (case 2)

\section{Countermeasures}

In order to reduce the infrasound pressure and reduce the amplitude of the bridge vibration modes with the same phase in each span (Fig. 2(a)) and with the secondary mode shape (Fig. 2(b)), two types of countermeasures are proposed below.

\subsection{For the bridge vibration modes with the same phase}

When the infrasound problem induced by the bridge vibration modes with the same phase (Fig. 2(a)) occurs, we propose installing a viscoelastic damper at the end of the girders [17], as shown in Fig. 14, to suppress the vibration mode.

The viscoelastic damper consists of three plates and viscoelastic material. One plate installed in the lower flange of the girder, is sandwiched by the two plates cantilevered from the abutment. In addition, the viscoelastic material is installed between above two plates. This damper obtains the damping effect by changing the rotation angle at the ends of girders into shear deformation of the viscoelastic material. It restrains the vertical bending vibration by changing the vertical displacement 
into the angular displacement (or longitudinal displacement), as shown in Fig. 15(a). Though a lateral vibration is not restrained by this damper, a torsional vibration accompanied with a vertical displacement can also be restrained, as shown Fig. 15(b).

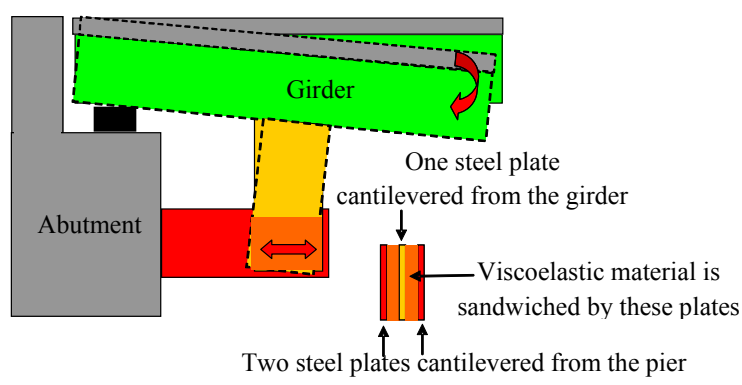

Fig. 14 Viscoelastic damper at the end of the girders

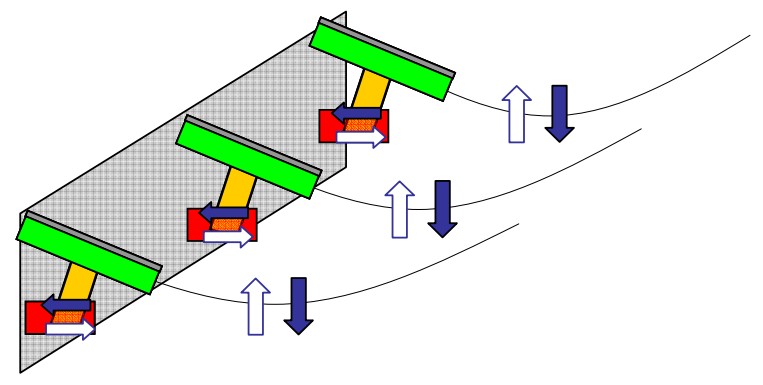

(a) Vertical bending vibration

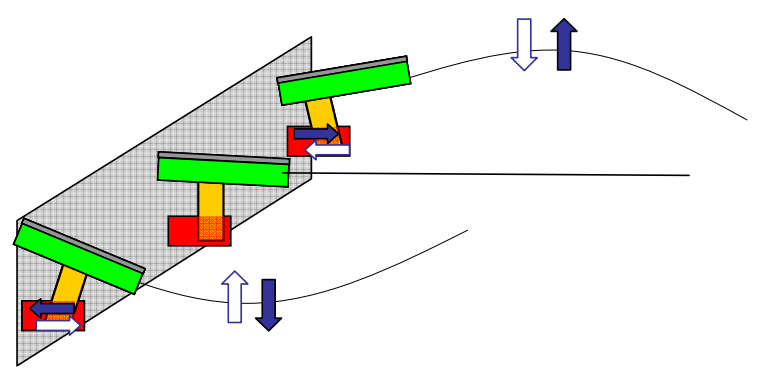

(b) Torsional vibration

Fig. 15 Behavior of damper by each vibration

\subsection{For Vibration modes with secondary mode shape}

When the infrasound problem induced by the bridge vibration modes with secondary mode shape at the frequencies of 10-20 Hz (Fig. 2(b)) occurs, we can adopt the extended deck method [15], as shown in Fig. 16, to reduce the impact force of the tire spring vibration (10$20 \mathrm{~Hz}$ ), when the heavy trucks pass over the roughness (faulting) at the expansion joint.

The extended deck method is that the existing reinforced concrete deck is extended in the direction of the embankment, and the expansion joint is moved on the approach embankment. The length of the extended deck was determined to be $10 \mathrm{~m}$ considering the time of damping in the tire spring vibration.

Some problems arise at the expansion joint: (1) noise is caused by expansion joints, such as a modular expansion joint [18]; (2) bump and faulting are caused by the settlement of the approach slab [19-20]. An extended deck can prevent these problems.

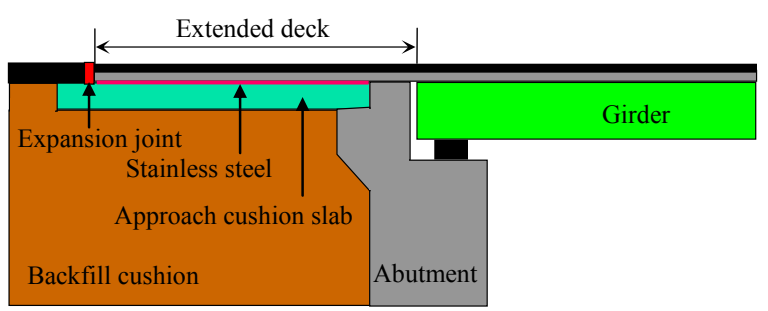

Fig. 16 Extended deck method

\section{Conclusions}

This study clarifies the relation between the infrasound and the continuous steel bridge vibration modes, which is generated by the vibration of the moving heavy trucks using several experimental results. The following conclusions can be drawn:

(1) The continuous steel bridges of case 1 and case 2 have the vibration modes with the same phase in each span at the frequencies of the truck's suspension spring vibration. They also have the secondary mode shape ( 2 nd bending vibration mode) at the frequencies of the truck's tire spring vibration, by comparing the frequency of the infrasound and results of the vibration mode.

(2) The residences considered in case 1 and case 2 are influenced by the vibration modes with the same phase in each span at the frequencies of the truck's suspension spring vibration $(3 \mathrm{~Hz})$, along with the secondary mode shape at the frequencies of the truck's tire spring vibration $(10-20 \mathrm{~Hz})$.

(3) The bending vibration modes with the same phase in each span have the most powerful infrasound pressure, since each span vibrates with the same phase.

(4) The vibration mode with the secondary mode shape $(10-20 \mathrm{~Hz})$ is caused by the trucks' tire spring vibration when the trucks pass over the roughness (faulting) at the expansion joint.

(5) This study proposes the viscoelastic damper at the end of the girders and the extended deck method to reduce the amplitude of the bridge vibration modes with the same phase in each span and with the secondary mode shape, respectively. 


\section{References}

[1] Y. Kitamura, T. Yamada, A study on infrasound caused by road traffic, Nihon Doro Kodan Research Institute report, 1975: 324-344 (in Japanese).

[2] K.Imaichi, Y. Tsujimoto, Theoretical analysis of infrasound radiation from an oscillating bridge, Journal of Sound and Vibration, 1982, 81(4): 453-468.

[3] S. Tsunekawa, Y. Kajikawa, S. Nohara, , et al., Study on the perceptible level for infrasound, Journal of Sound and Vibration, 1987, 112(1): 15-22.

[4] Y. Ding, X. Xie, H. Li, et al., A numerical method for analyzing the low-frequency noise of bridge under vehicle load, In: Proc. of the 2nd International Conference on Transportation Engineering, Chengdu, 2009: 37063711.

[5] Q. Li, Y.L. Xu, D.J. Wu, Concrete bridge-borne lowfrequency noise simulation based on train-track-bridge dynamic interaction, Journal of Sound and Vibration, 2012, 331(10): 2457-2470.

[6] Q. Li, D. Wu, J. Han, Sound induced by local vibration of railway bridge, In: Proc. of 5th International Symposium on Environmental Vibration, Chengdu, 2011: 503509.

[7] T. Chanpheng, H. Yamada, T. Miyata, et al. , Application of radiation modes to the problem of low-frequency noise from a highway bridge, Journal of Applied acoustics, 2004, 65(2): 109-123.

[8] S. Fukada, Infrasound and Vibration of Short Span Bridge due to Running Vehicle, In: Proc. of Inter-noise, Hawaii, 2006: No.078 (on CD-ROM).

[9] H. Hama, S. Fukada, M. Sugimoto, et al., Characteristics of infrasound radiated from the continuous short spans bridge due to running trucks, In: Proc. of Low Frequency, Tokyo, 2008: 27-34.

[10] C.Broquet, S.F. Bailey, M. Fafard, et al., Dynamic behavior of deck slabs of concrete road bridges, Journal of Bridge Engineering, 2004, 9(2): 137-146.

[11] G. Cantisani, G. Loprecipe, Road roughness and whole body vibration: evaluation tool and comfort limits, Jour- nal of Transportation Engineering, 2010, 136(9): 818826.

[12] Y. Kajikawa, S. Fukada, T. Hayashishita, et al., Vibration characteristics of highway bridge due to running vehicles with different suspensions. Journal of Structural Engineering of Japan, 2004, 50: 413-420 (in Japanese).

[13] F.G. Mark, C. David, J.C. David, Effects of vehicles suspension design on dynamics of highway bridges, Journal of Structural Engineering, 1995, 121(2): 272282.

[14] Ministry of the Environment (Japan), a guidebook for low frequency noise. http://www.env.go.jp/air/teishuha/ tebiki/04.pdf (in Japanese).

[15] S. Fukada, Y. Kajikawa, M. Sugimoto, et al., Characteristics of vibration and low frequency noise radiated from the highway bridge and countermeasure, In: Proc. of 19th International Congress on Acoustics, Madrid, 2007: ENV11-001-IP (on CD-ROM)

[16] H. Hama, S. Fukada, K. Usui, et al., Infrasound and ground vibration transmitted from highway bridge using moving trucks, In: Proc. of 20th International Congress on Acoustics, Sydney, 2010 (on CD-ROM).

[17] S. Fukada, T. Yoshimura, T. Okada, et al., Application of dampers for environmental vibration problem occurred nearby highway bridge, In: Proc. of the 4th International Symposium on Environmental Vibrations, Beijing, 2009: 271-276.

[18] K.A. Ravshanovich, H. Yamaguchi, Y. Matsumoto, et al., Mechanism of noise generation from a modular expansion joint under vehicle passage, Engineering Structures, 2007, 29(9): 2206-2218.

[19] H.L. Zhang, C.S. Hu, Determination of allowable differential settlement in bridge approach due to vehicle vibrations, Journal of Bridge Engineering, 2007, 12(2): 154163

[20] X. Shi, C.S. Cai, S. Chen, Vehicle induced dynamic behavior of short-span slab bridges considering effect of approach slab condition, Journal of Bridge Engineering, 2008, 13(1): 83-92.

(Editor: Junsi LAN) 